University of New Hampshire

University of New Hampshire Scholars' Repository

3-1-2017

\title{
Information Literacy Instruction in an English Capstone Course: A Study of Student Confidence, Perception, and Practice
}

\author{
Susanne F. Paterson \\ University of New Hampshire, Manchester, Susanne.Paterson@unh.edu \\ Carolyn B. Gamtso \\ University of New Hampshire, Manchester, carolyn.gamtso@unh.edu
}

Follow this and additional works at: https://scholars.unh.edu/unhmlibrary_pub Comments

This is an Author's Original Manuscript of an article published by Elsevier in The Journal of Academic Librarianship in 2017, available online: https://dx.doi.org/10.1016/j.acalib.2016.11.005. This manuscript version is made available under the CC-BY-NC-ND 4.0 license http://creativecommons.org/licenses/by-nc-nd/4.0/

\section{Recommended Citation}

Paterson, Susanne F. and Carolyn White Gamtso. "Information Literacy Instruction in an English Capstone Course: A Study of Student Confidence, Perception, and Practice." The Journal of Academic Librarianship. 43:2 (2017): 143-155. doi:10.1016/j.acalib.2016.11.005

This Article is brought to you for free and open access by the Library at University of New Hampshire Scholars' Repository. It has been accepted for inclusion in Library Community Scholarship by an authorized administrator of University of New Hampshire Scholars' Repository. For more information, please contact

Scholarly.Communication@unh.edu. 
Information Literacy Instruction in an English Capstone Course: A Study of Student Confidence,

Perception, and Practice 


\begin{abstract}
An English professor and an instruction librarian at XXX felt that the college's new English Capstone course for majors provided a unique opportunity to assess the information literacy skill levels of graduating English majors. They therefore engaged in a three-year study to evaluate the IL competency of these students, to gauge their perceptions of library instruction provided during the Capstone course and throughout their academic careers, and to determine students' confidence and self-efficacy with respect to these skills. The researchers sought to determine the ways in which the IL program for English majors effectively met established IL goals and to identify areas for improvement.
\end{abstract}

\title{
Keywords
}

information literacy; library instruction; faculty/librarian collaboration; student perceptions of information literacy; student confidence; student self-efficacy

This research did not receive any specific grant from funding agencies in the public, commercial, or not-for-profit sectors. 


\section{Introduction}

At XXX, instruction librarians and English instructors collaborate to provide students in the college's English program with course-integrated, assignment-specific information literacy (IL) sessions. The IL sessions are presented by librarians in English gateway, upper-level, and Capstone classrooms. The sessions are carefully woven into the professors' class plans and are designed to help students develop the research skills necessary to successfully complete research projects in the course and in the discipline. Through in-class librarian-led demonstrations and exercises in relevant databases, and through graded library assignments (such as annotated bibliographies), students are exposed to the breadth of primary and peer-reviewed sources considered essential for English scholars. The IL skills introduced in the classroom visits are reinforced in scheduled follow-up consultations with reference librarians, where students receive personalized assistance with their individual research projects.

While English majors at XXX receive multiple IL sessions in a variety of courses during their academic careers, the instruction librarians and English professors noted that the sessions were offered as "stand-alone" lessons within each course, with little continuity from course to course through the academic program. Because of this lack of a cohesive, formalized IL plan in the English program curriculum, librarians became concerned that individual students could be missing essential IL information while being overexposed in other areas, depending on their sequence of courses. In an effort to address this concern, an instruction librarian and an English teacher partnered to assess the IL skill levels of graduating seniors enrolled in English Capstonelevel courses over a three-year period. The study explored the students' subjective perceptions of the IL instruction they had received during their time at the university, their demonstrated IL competencies, their confidence in their own IL skills, and their self-efficacy or persistence in 
seeing their research through to completion. This essay describes the results of this study and discusses its implications for the future of the IL curriculum in the English program and at the college as a whole.

\section{Background}

\section{Institutional Context}

XXX is a college of the XXX. Located 45 miles from XXX, the predominantly commuter college serves the diverse population of XXX, the state's largest city, and surrounding communities. XXX enrolls approximately 1100 students and has a student/faculty ratio of 11:2 ("At a Glance"); its small size and commitment to interdisciplinary endeavors make the college an ideal environment for forming cross-departmental collaborations and for piloting new academic initiatives.

Taking advantage of the opportunities afforded by XXX's culture of innovative partnerships, the librarians reach out to faculty collectively and individually, encouraging them to invite librarians to their classes to instruct students in the use of relevant library resources and in the development of IL skills. Librarians collaborate with the First Year Writing Coordinator and with the director of the college's First Year Experience Program to structure a carefullyscaffolded library instruction experience during students' first year at the college. therefore, the $\mathrm{IL}$ instruction program at XXX consists of a robust first-year library instruction sequence: instruction librarians visit all First Year Writing and First Year Seminar (FYS) classes to introduce IL topics.

In the early years of these partnerships, instruction librarians used the Association of Research Libraries' (ACRL) Information Literacy Competency Standards (2000) as a guide for 
developing lesson plans and for assessing outcomes at the freshman level. Specifically, instruction librarians addressed Standard One (The information literate student determines the nature and extent of the information needed) and Standard Two (The information literate student accesses needed information effectively and efficiently) during in-class IL sessions in First Year Writing and FYS classrooms. A collaboration with the college's tutoring center to train writing tutors in IL skills and concepts (XXX et al., 2016) addressed Standard Four (The information literate student, individually or as a member of a group, uses information effectively to accomplish a specific purpose): through writing tutorials, the tutors worked with students to successfully integrate research sources into their composition papers. With the adoption of the ACRL's Framework for Information Literacy for Higher Education in 2016, instruction librarians have redesigned the first-year IL program to reflect the IL frames, which serve as touchstones for in-class skills instruction and practice (XXX et al., 2016).

After the first year, however, the college's IL program lacks consistency, with students in some disciplines receiving IL instruction in many courses, and students in other disciplines receiving little or no instruction beyond their First Year Writing and FYS courses. While many faculty members in a variety of disciplines work with librarians to develop course-specific inclass and/or online IL instruction at all levels, from discipline gateway through graduate-level courses, these collaborations respond to student needs in particular classes as they complete particular assignments. As a consequence, there is little cohesion in the presentation of material from one class to another, nor is there a progression of IL skills as students move through their course sequences. Faculty and librarian efforts to create such cohesion are in the early stages in several disciplines, including in the English program; however, the XXX librarians have yet to engage in the curriculum mapping necessary for a comprehensive four-year college-wide IL 
plan. Such a plan would ensure that students are introduced to core IL concepts in a

developmental fashion, with each concept taught building on those introduced in earlier courses and sessions. While the instruction librarians are gradually incorporating the Framework document into their upper-level IL instruction as well, the Capstone-level IL lessons described in this essay were designed with the ACRL's Standards as guideposts.

It was their desire to explore developing a multi-year, comprehensive IL plan for the XXX English program that led the authors, an English teacher and an instruction librarian, to conduct a study of the IL perceptions, skill levels, confidence, and self-efficacy of English majors undertaking their Senior Capstone course. The colleagues have collaborated on IL instruction sessions and assignments in the past, from First Year Writing classes to upper-level English literature courses (XXX \& XXX, 2004; XXX \& XXX, 2005/2006; XXX \& XXX, 2011). They always schedule their IL sessions at the point in the semester when students are starting the research process; they present multiple IL sessions during the course of a semester so that skills learned in one session can be reinforced and built upon in the next; they design the sessions to be interactive, stressing student participation and discussion; and they co-teach the classes, with the instruction librarian and the English teacher actively leading classroom activities together, thus reinforcing the points made by one another and demonstrating the link between effective library research and effective writing. Given their history of successful classroom partnerships, they embraced the opportunity to develop effective instruction at the Capstone level, and to use the course to evaluate the research skills of graduating English majors so as to assess the effectiveness of their IL teaching. The goal of IL pedagogy in the XXX English program was to graduate students who had mastered all five ACRL information literacy standards, from formulating research questions, to creating search strategies, to evaluating materials, to ethically 
incorporating information into a paper or project (ACRL, 2000). A formal assessment of students at the Capstone level would indicate the extent to which the goal had been achieved. The following section describes the evolution of the English Capstone experience and the development of IL instruction for the course.

\section{History of the English Capstone}

In 2012, the residential faculty of the English program at XXX began to implement across the curriculum a requirement to have a Capstone experience for students in the major. It was felt that students needed a "cumulative" experience, which would pull together all the key skills they had been exposed to and developed during their time as English majors, as well as give them an opportunity to showcase an area of personal interest to their cohort members. The requirements would be fulfilled in the final or penultimate semester of the students' program of study by taking a senior-level course and, in consultation with the classroom instructor for that course, determining the additional course requirements that would fulfill the Capstone designation. In the coauthor's courses this consists of an Annotated Bibliography assignment (Appendix A) which requires students to locate, retrieve, and evaluate a number of scholarly sources related to their research topic, and a research paper (Appendix B) which is designed to expand investigation of a topic or text in class and extend it to become part of a scholarly conversation. Critical to both assignments is a robust, integrated sequence of IL presentations and hands-on exercises, designed to reach the students at point-of-need, and at different stages in the invention, discovery, research, evaluation, and incorporation process of the project.

Information Literacy in the English Capstone 
The IL instruction for the English Capstone class consists of four hour-long sessions during the course of the term. During the first session, the librarian leads students in brainstorming exercises to help them access prior knowledge about their research topics, guiding them in the use of reference sources to gain background information and a focused research question. The second classroom session focuses on database searching and the students' Annotated Bibliography assignment. The librarian reviews the basics of source evaluation and asks students to explore relevant databases on their own, using a course-specific LibGuide as a springboard. Once the students explore the suggested databases, the librarian asks them to choose an article and discuss the processes they used to assess its suitability for a college research project. Through student presentations and discussion, the class explores the criteria scholars use to evaluate an article and to place it within the disciplinary discourse on an issue. At the end of the session, the English teacher and the librarian ask the students to read one of the selected articles for homework and come to the next IL session (scheduled for two weeks later) prepared to discuss it with their teachers and their peers.

During the third IL session, the librarian and the English teacher introduce students to the elements of an Annotated Bibliography, using guidelines provided by the Online Writing Lab at Purdue University (https://owl.english.purdue.edu/owl/resource/614/01/). These guidelines are particularly useful because they prompt students to engage in robust analytical activity when they complete their annotations. Guided by the co-teachers, the students together write an annotation of the article they read for homework, thus allowing them to practice the skills necessary for successful completion of the Annotated Bibliography assignment, their first step in the semester-long research process. The session closes with the librarian conducting a questionand-answer session to address any confusion students may have regarding their own topics and 
how best to begin searching for appropriate, scholarly sources. The librarian returns toward the end of the term for one more in-class session, which begins with an open-ended question-andanswer period, followed by a librarian-assisted workshop.

In the time between the database session and the Annotated Bibliography session, the classroom teacher requires the students to meet with the librarian for 30-minute one-on-one research consultations. These student-librarian meetings are a core component of the IL instruction in the Capstone course, as it is through these conversations that the librarian is able to address student research needs in an immediate and personalized manner. During the one-on-one sessions, the librarian becomes students' personal research guide as they navigate increasingly sophisticated databases and build complex search strategies. Many of the students elect to meet the librarian more than once during the course of the semester as their topic exploration becomes more focused and the need for highly-specialized research tools becomes apparent. This mentoring relationship builds students' confidence in their own abilities, as they realize that they are becoming experts in their topic and have the necessary skills to complete a project that may have seemed daunting at the start of the semester.

\section{Literature Review}

\section{Student Perceptions of IL Instruction}

Any review of the literature surrounding students' perceptions of IL instruction must consider their attitudes toward the academic research process itself, as those attitudes will directly impact their opinions of library sessions. Recent studies have revealed that college students' views toward secondary research are not uniformly positive. Klentzin (2010) observed that many of the students in her study confessed to having "adverse emotions and attitudes 
towards the process" (p. 557) of research, while Denison and Montgomery (2012) discovered that most of the students they surveyed found research to be "difficult and frustrating" (p. 387), leading some to take the perceived easy route of using unvetted Internet sources rather than peerreviewed literature. The same studies demonstrated that these negative attitudes and behaviors could be lessened through positive student/librarian relationships and interventions (Kwon, 2008); through an increase in students' critical thinking skills (Kwon, 2008); and through carefully-structured assignments that gave students a sense of personal interest in a topic, as well as feelings of pride in and ownership of the product (Denison \& Montgomery, 2012; Dubicki, 2015; Klentzin, 2010). The students interviewed by Gross and Latham (2009), while not generally concerned with the reliability of sources consulted to fulfill a personal information query, did change that view when "the information need that is motivating the search is important or crucial in some way" (p. 181). Getting students to "buy in" to a research task is essential to motivate them to develop necessary IL skills.

Accordingly, student perceptions of IL instruction shift depending on the teaching methodology and other structural and pedagogical factors. Detlor et al. (2012) discovered that students responded well to IL sessions that involved active learning techniques: after engaging in such sessions, students reported an alleviation of library anxiety, an increased sense of confidence using library resources, and a willingness to seek out librarians for assistance. Kim and Shumaker (2015) noted that students in classes where IL sessions were linked to a particular assignment and were presented at the point-of-need ranked the instruction higher than students in classes where the skills were not reinforced with an actual research project. A study of the research processes of upper-level undergraduate and graduate students conducted by Dubicki (2015) reinforced these findings: students mentioned library instruction as being helpful when it 
was "embedded in courses" (p. 677) and when the skills were deployed immediately to fulfill the requirements of an impending research task (p. 684). Dubicki also discovered that students found IL sessions to be most effective when offered in conjunction with research help outside the classroom.

\section{Student Confidence}

In determining the extent to which students felt that IL instruction was helpful, the instruction librarian and English teacher were focused on a number of concerns. A primary interest was the level of confidence students exhibited in their ability to carry out research. The instruction librarian and English teacher were particularly interested in the data which indicate a correlation between students' overconfidence in their research skills and a resistance to research instruction, a manifestation of the dichotomy whereby students have poor IL skills but have significant confidence about their skills observed by Gross and Latham (2009) and Wilkinson and Crews (2009). Such a correlation can come about because of students' repeated exposure to IL sessions, and the repetitive content of these sessions (Bandyopadhyay, 2013, p. 195). It was important for the colleagues to determine if students were experiencing IL instruction overload because of the number and similarity of instruction sessions they had been exposed to over the course of their degree program.

Complicating the issue is that students' perceptions of these sessions' utility could be skewed by their perceptions of their own IL skills. Students might not have the requisite knowledge of their research skills to evaluate what they are learning and their own performance as competent researchers. As Bandyopadhyay noted, "people who lack competence tend to be unaware of their inabilities" (2013, p. 199). The determining factor between confidence and 
overconfidence is likely to be students' actual skill-level with respect to research (Gross \& Latham, 2007). There is a need to be cautious about evaluating students' perceptions of what they think they know, balancing these carefully with what students demonstrate when they apply those skills because, as Molteni observes, students' "confidence does not appear to be a reliable indicator of competence" (2015, p. 5). Ironically, the more students learn about IL and applying those skills effectively, the more they realize what they don't yet know (Polkinghorne \& Wilton, 2010, p. 468). As students develop more advanced IL skills, they also develop increased "metacognitive skills" which, in turn, allow them to "make better estimations of their own performance" (Gross \& Latham, 2009, p. 337). If librarians and classroom teachers are looking for accuracy in students' perceptions of their IL competencies, they must be alert to the fact that students themselves need assistance in evaluating their own abilities; it is a matter of instructors recognizing that "students lack the awareness to assess their skill level without guidance" (Jackson, 2013, p. 151). Any self-assessment librarians and classroom teachers ask students to engage in with respect to such skills needs to be seen in the context of just how much effective instruction has been deployed to help students acquire those skills in the first place.

\section{Student Self-Efficacy}

Related to students' feelings of confidence about their abilities to carry out research is their self-efficacy, or their willingness to persevere with a research project. Self-efficacy "determine[s] whether coping behavior will be initiated, how much effort will be expended, and how long it will be sustained in the face of obstacles and aversive experiences" (Bandura, 1977, p. 191). Perseverance—or what O'Neill et al. called "persistence" (2012, p. 525)—is recognized as a key element of "learner disposition," and is critical in shaping students' readiness to learn 
and succeed, particularly in the college context (Donham, 2014, p. 1). For the colleagues, information about students' perseverance is helpful in designing a scaffolded project which provides instruction on a just-in-time basis, as it can shape the duration of the assignment and the types of IL instruction delivered.

It is hoped that the eventual outcome of students' persistence will exceed what ParkerGibson defines as the "Principle of Least Effort," where, in this case, high-school students deployed only as much effort as was required to get a grade which was, to them, adequate (2001, p. 65). Instead, the effort would reach at least a point where meaningful learning takes place and IL skills are used in ways that robustly advance students' cognitive functioning. Such an effort is conscious by students, in that students essentially decide how much and what kind of effort (both academically and emotionally) they can commit to a research assignment, as Valentine (2001, p. 109) has expertly demonstrated. Thus the assignment itself must be designed in such a way as to make the case to students as to why they should meet the instructor halfway. It needs to be created purposefully to build on students' content-level interests and IL skills and yet also move those skills forward in a just-challenging-enough fashion.

\section{Methods}

The English teacher taught upper-level courses that seniors could take for Capstone credit five times from the fall semester of 2012 to the fall semester of 2015 . The authors surveyed only those students who were enrolled in the courses for their Capstone experience. While the course content and student research topics differed from class to class, the in-class IL instruction followed the same pattern and basic lesson plan, so the IL experiences of all of the Capstone students in the courses surveyed was consistent. 
The study entailed two online Survey Monkey questionnaires, a pre-course and a postcourse test (Appendix C). Each was designed to measure students' actual research practices through multiple choice and applied skills questions, while open-ended reflection questions elicited their subjective perceptions of their own IL competencies and their attitudes toward IL instruction. The multiple choice and applied questions in the survey tool addressed skills outlined in the ACRL Standards document (2000), specifically the performance indicators enumerated in Standards One (formulating research questions), Two (choosing databases and creating search strings), Three (incorporating sources), and Five (citing sources and avoiding plagiarism).

Students were asked to create ID numbers that would protect their identities but would allow the coauthors to match pre-course and post-course responses. The pre-course test was administered by a third party on the first day of class, and included a reflection question asking students to look back on the library instruction they had received in the past, to describe their own typical research process, and to describe themselves as researchers. The post-course test was administered on the last meeting day of class, also by a third party, and included the same multiple choice and open-ended applied skills questions as the pre-course test. The post-course reflection question asked students to describe how (or if) they had grown as researchers as a result of the IL instruction, the Annotated Bibliography assignment, and the research paper in the Capstone.

A total of 18 students took the pre-course test and 15 students took the post-course test during the span of the five semesters. The sample numbers reflect the small size of the college, as well as the number of enrollments in the English program as a whole. It should be noted that some seniors choose to take their Capstone course with other instructors in the English program; this study surveyed only those students in the coauthor's classes, thus limiting the sample size. 
The disparity between the number of students taking the pre-course test and the number taking the post-course test can be attributed to student absenteeism on the last meeting day of the class. While students not present for the final in-class meeting were encouraged to take the post-course test on their own time, not all did so. In addition, some of the participating students chose not to complete all of the survey, so the coauthors do not have complete participant data for every question. This exploratory study gives a snapshot of this specific student population's experiences with IL in these particular courses over a three-year period.

\section{Results and Analysis}

Student Perceptions of Research and of IL Instruction

\section{$\underline{\text { Pre-Course Survey Results }}$}

One of the concerns of the coauthors going into the study was that students would consider IL instruction in the English program, and in the college as a whole, to be repetitive and/or to lack structure and coherence. It was gratifying to discover that almost all of the English Capstone students found IL instruction to be useful to them as researchers. Students responding to pre-course survey Question 2 indicated that IL sessions made "the research process . . . a lot easier"; "have been invaluable"; and were "very useful and informative." While many students focused on the utility of the more technical aspects of library instruction (such as keyword generation, Boolean operators, and efficient use of online databases), others indicated that the IL sessions helped them more globally with brainstorming, drafting, and evaluation of sources. One student noted that "Information Literacy has changed the way I evaluate the authenticity of the materials I use for reference in my papers." Another student stated that he or she was more likely to look in multiple sources to gain knowledge of a topic, commenting, "From the training I've 
received so far I find myself seeking information from man[y] more sources and [am] better able to connect what I read to issues and topics not necessarily related to my topic. This strength I feel gives me better insight and a deeper understanding of whatever it is I'm researching." In keeping with research indicating that students respond best to active learning techniques in IL pedagogy (Detlor et al., 2012), one student specifically mentioned the utility of First Year Writing instruction at XXX (where there is a high level of IL support) in which "the course structure allows for the application of [information literacy] skills."

Again confirming research suggesting that students particularly benefit from follow-up one-on-one research consultations, several students expressed that they turned to librarians and instructors to build upon skills learned in class, one saying, "When I forget, I have a librarian to help me." This comment confirms that the Capstone instruction practice of requiring students to consult with a reference librarian increases students' confidence in their own ability to complete a research project. Rather than finding the IL sessions redundant, one student specifically benefited from practicing the skills multiple times. He or she observed, "I have found that the repetition in instruction has been useful in cementing the research process and allowing it to become an experience where my focus is not diverted by technical insecurities, but remains on the content of the information I find and on my paper's subject." This insight underlines the need for scaffolding in the presentation of IL skills: because sessions built on the student's existing knowledge base and provided multiple opportunities to apply those skills, the student was able to progress to higher-order thinking regarding the nature and use of materials found.

In contrast to the enthusiasm students expressed about IL instruction, they were more guarded in their feelings about the research process generally. Studies in the area of student perceptions of the research process (Klentzin, 2010; Denison \& Montgomery, 2012; Ganley et 
al., 2013) dovetailed with subjective responses to pre-course survey Question 2, revealing that several Capstone seniors still found the research process challenging and did not feel themselves entirely up to the task. These feelings of frustration persisted despite the fact that the same students indicated that they found the IL instruction they had received to date to be helpful. One student commented that he or she felt that "[t]he instruction on literacy information has made researching topics for papers as well as research itself easier." However, the student went on to say that research was "still not enjoyable." Another student acknowledged that the IL instruction "has helped me understand which databases are the best for certain subjects. It has also helped me to organize my research process." This student's positive comments regarding IL instruction were, however, immediately followed by these caveats: "As a researcher, I typically have some difficulty finding enough useful information through the databases. I think that researching can be frustrating at times."

Some students acknowledged that the IL instruction they received during their first three years in college helped them to a point, but not enough to give them the skills they felt were needed to complete a major senior-level assignment. One student who expressed strong enthusiasm for IL instruction at the college ("I feel as though the IL instruction classes I have participated in have been invaluable to me as a researcher") concluded the reflection essay with a statement indicating that he or she still had a feeling of deficit: "I do feel as though my knowledge is explicitly limited to what I have learned through the instruction sessions that I have participated in." This student understands that he or she has not gained a full mastery of the research process despite absorbing the skills taught in IL sessions. Some students suggested reconfiguring the IL program at the college to offer a more robust and structured education in IL skills. One student believed that IL instruction, while useful, had not given him or her the skills 
necessary for successful research. This student offered a solution to the problem: "It would have been helpful for me to have take[n] a class in my first semester that would have been taken in addition to Freshman English." These comments confirmed for the coauthors the need for a more structured four-year IL plan to ensure that students embarking on their Capstone experience possessed the skills necessary to enthusiastically engage with the research task at hand.

\section{$\underline{\text { Post-Course Survey Results }}$}

The student responses to post-course survey Question 2 specifically mentioning library instruction further validated the need for a scaffolded approach to IL. Several students stated that the in-class IL sessions helped jumpstart their research processes; however, they also indicated that the sessions were helpful because they offered a review of skills already taught in other sessions. One student made this observation explicitly, noting, "The [information] literacy instruction was useful in its ability to serve as a refresher on what to look for in articles ... I don't feel I have gained any new experience or knowledge in terms of researching that I did not already possess. It was interesting and helpful to use this paper as a refresher course in research work." Although this student was already familiar with IL concepts and research strategies, the Capstone IL sessions reinforced those skills at the point-of-need and in the context of the particular course. Library research strongly suggests that such scaffolded IL instruction, in which instructors use students' prior knowledge as a springboard to the development of new understanding, leads to increased student comprehension and retention in the long term (Malenfant \& Demers, 2004; Radom \& Gammons, 2014). Another Capstone student (also a peer tutor) alluded to the benefits of scaffolding, remarking, "The library instruction allowed me to see possible databases to use for different aspects of my thesis ... Completing the Capstone experience strengthened my skills as a researcher. Though I felt comfortable showing others the 
subject-specific databases in tutorials, I had never really used them myself. Now that I have this experience I can better evaluate where to look for sources, both for myself and my tutees." These observations revealed how IL instruction in the course encouraged this student to put conceptual knowledge to practical use.

While students indicated that the in-class IL sessions were largely recaps of information they had covered in other courses, many found the one-on-one research consultations with the instruction librarian to be especially beneficial. It was during these meetings that students went beyond skills covered in past courses and learned new IL concepts and skills. As Bordonaro and Richardson (2004) documented, students gain confidence when they are provided with peer, faculty, and librarian assistance as they learn new skills and concepts. This was true for the Capstone students, one of whom expressed his or her progression from skills mastered previously to new knowledge and practices: "My research strategy was heavily impacted by my literacy instruction. Prior to this semester, I had been a part of several informational sessions with $\mathrm{XXX}$ [XXX, instruction librarian and coauthor], [sic] however the more individual discussions we had this semester were particularly helpful." The student's insights suggested that IL instruction in the English Capstone course should persist with and perhaps expand its focus on one-to-one meetings, with the librarian continuing to consult with and mentor students. This embedded approach appears to have been a successful strategy to address individual students' IL skill levels and guide them wherever they are in the research process.

\section{Student Confidence}

\section{$\underline{\text { Pre-Course Survey Results }}$}


Examining students' perceptions of their confidence as researchers in the pre-course test, the instruction librarian and English teacher noted that students generally felt confident in their research or IL skills. The open-ended Question 2 (Appendix C) only elicited one comment referencing lack of confidence: "I am not very confident when conducting research, as I never know what the professor wants," a phenomenon noted by Valentine (2001, p. 109). To find such a comment at the end of a student's educational experience is disheartening, as it indicates that instruction has not effectively communicated the importance of research as an inherently valuable analytical experience, rather than an arbitrary hoop to be jumped through. When it comes to designing IL instruction, more effort needs to be made to meet such students at a place of interest and intellectual ability throughout their college career.

More common were comments which implied a reasonable or even high level of confidence in students' IL skills. The pre-course test Question 2 elicited such responses as, "I wouldn't go so far as to call myself a professional, but I do feel as though I have a good idea of how to find sources necessary for my topic, and am reasonably confident about my ability to find the information required to write about a certain topic." Another student reflected with assurance on his or her progress by focusing on credibility of sources as a marker of IL skills development: "My interpretation of what was acceptable to use as a source was much looser before I got to college. Now I only use sites that have been verified by the academic peerage [sic], or that I know can be held responsible for disseminating false information." Here, the student explicitly linked a research skill to confidence as a researcher, demonstrating that previous IL sessions positively impacted his or her analytical abilities. Supporting this was a comment from a student who noted, "I feel as though the IL instruction classes I have participated in have been invaluable to me as a researcher. Now that I am embarking on my capstone experience, I feel as though I 
am fairly well prepared to conduct research and find useful and relevant sources for my upcoming paper." There are two things to observe here: the student acknowledged the cumulative nature of IL knowledge over time; and the student's confidence was present but guarded ("fairly confident"). There was no sense of trepidation about undertaking research, but rather a recognition of the skills already learned and an implicit anticipation that more skills would be acquired in the process of the Capstone course.

The issue of moderate confidence marks a student as an experienced researcher if that confidence is characterized by specific recourse to IL skills. A similar cautious confidence in research skills was apparent in the admission, "I don't find myself needing much guidance in the process of finding resources, but rather input in the content that is included within the research paper itself." As Bandyopadhyay noted, "mere access to information does not enhance students' knowledge and understanding of the information they receive" (2013, p. 199). However, only someone who has been exposed to numerous effective IL instruction sessions would be able to characterize his or her skill-set this cogently. The student made a distinction between technical knowhow, i.e. the ability to retrieve source material, and analytical thinking skills, i.e. the ability to effectively incorporate this material into the research project. Another student showed similar moderation in his or her confidence, acknowledging that "As a senior, I feel mostly prepared for my Capstone class. I know there are still things I do not know about researching, especially since a lot of my experience is within two or three databases. I hope to gain an understanding of more than just my standard databases." As was noted earlier, the more students develop IL skills, the more effective they are at pinpointing their strengths and deficiencies as researchers; one can only analyze one's IL skills from a point of experience, rather than a point of lack of knowledge. Post-Course Survey Results 
When the post-course test responses to Question 2 were examined with respect to confidence, the instruction librarian and English teacher noted that most students felt they were somewhat confident overall as researchers and, importantly, were able to provide specific reasons for this (unlike in the pre-course responses). These reasons can be categorized in two ways: as tool-based, and as critical-thinking-based. The former would include comments such as, "After finishing the capstone I feel more confident as a researcher. I know specific words to use and how to properly use research in a paper," which emphasized search terms and incorporation of sources into writing; also, "Determining different keywords and search terms yielded different and helpful results with each new search. I feel like my research has improved, though I am still not as confident as I should be," which emphasized technical skills in retrieving information. Despite the latter student's feelings that he or she didn't measure up to the confidence-level he or she should have had at this stage (a level left unspecified by the student), the response to the individual skills acquired demonstrated a level of knowledge which marked a confident researcher. This response may reveal a case of having high skills but moderate-to-low confidence, whereby a student acquires more knowledge of his or her skills and as a consequence is better able to estimate skill deficits (Gross \& Latham, 2009, p. 337). One student remarked on pushing the boundaries of experience when using tool-based skills, stating, "I went outside of my comfort zone of Project Muse, Academic Search Premier, and JStor, and used Psychology and Sociology databases, as well as others." This shows that, even if he or she had not been confident with these new databases, there was a desire to overcome this lack of security and do what was necessary to engage in robust research regardless. Paradoxically, in doing so, the student did display a high level of confidence in his or her IL skills. 
Critical-thinking-based reasons for students' confidence as researchers illustrated their thoughtfulness about how IL impacted them as thinkers and writers. A student addressed the link between research and writing, commenting, "As a researcher, I believe I have grown through this course. I have learned how to utilize research into my article [sic] without disrupting the narrative." This was something the class focused on when discussing source incorporation and the Annotated Bibliography assignment. Most reassuring was this insightful comment from a student: "I feel as though my research skills are more developed after completing my Capstone experience. While I feel that I was already successful at determining which articles would NOT be of use to me, I now am more easily able to see how various articles can actually contribute to my research even if they are not exactly what I was hoping to find." Noteworthy was the focus on refinement of critical-thinking skills - that, as a result of skills developed during the course, the student was now a more discerning, perceptive reader of and thinker about the sources.

\section{$\underline{\text { Student Confidence in Practice: Pre- and Post-Test Results }}$}

While pre-and post-course test responses to Question 2 reveal insights from students about their confidence as researchers, actually testing students' IL skills confidence revealed some interesting data. Question 5 in the pre-course test (Appendix C) asked students the most efficient and effective way to access certain information for a specific topic. The correct answer was the first ("Use the following databases to find information on the topic: ERIC, MLA, LLBA, Sociological Abstracts"), and 29.4\% of respondents chose it; however, $41.18 \%$ of students selected the final choice ("all of the above"). The latter option revealed that students felt a scattershot approach to database research would be the most efficient and effective course of action to retrieve relevant information. The coauthors believe this demonstrated a certain lack of confidence in students' ability to deploy their IL skills effectively; it suggests that students 
hedged their bets by taking a one-size-fits-all perspective. It also revealed that students didn't yet have the requisite IL skills to determine the appropriate selection correctly, something which, at the senior level in college, is troubling. As has been noted earlier, students' perceptions of their IL skills is not always a reliable guide for those actual skills (Jackson, 2013, p. 151).

While one would assume some movement in data for the post-course test responses to Question 5, as students have completed their Capstone course and focused on building a research project, the colleagues were surprised at the results. The percent choosing the correct answer decreased to 21.43 , and the percent choosing the "all of the above" answer increased to 42.86 . Furthermore, the percentage of students choosing the second option, which focused mainly on literature databases, increased from $17.65 \%$ in the pre-course to $21.43 \%$ in the post-course test. To possibly account for this change, the English teacher and instruction librarian wondered if any of the following applied: one, were students still insecure researchers, preferring, as they did at the beginning of the course, a "shotgun" approach; two, were they more confident in their ability to read the retrieved materials and determine usefulness now that they had more practice over the course of the semester; three, were they more confident about using a narrower search string to retrieve sources (see Question 4 in Appendix C), applying it to a broader set of databases instead; four, were they familiar enough with databases outside their disciplinary fields (and were the instructors doing enough to make this happen); and finally, were students confident enough, like the student quoted above, to move outside of their "comfort zone" when they undertook research?

The qualitative data for Question 2 showed students generally had some confidence in their IL skills, as well as some awareness of their own shortcomings or anxieties as researchers; they also showed that students were specific about the skills they developed or refined which 
helped them gain confidence as researchers. Growth in students' self-awareness as learners and as IL practitioners was apparent. In contrast, the quantitative data for Question 5 were a mixed bag. It was clear that many students had deficits in their specific search skills when it came to databases, but the reasons for those deficits were difficult to determine with any certainty. Whether they were a matter of confidence, lack of skill, both, or something else entirely, there is a need to address database searching more extensively in future IL instruction.

\section{Student Self-Efficacy}

\section{Pre-Course Survey Results}

Students' perceptions of self-efficacy in the pre-course test tended to suggest a desire to stick with the projects and not give up easily. The pre-course test responses to Question 2 again provided some open-ended qualitative data on students' persistence, with a couple of students foregrounding the issue of procrastination. After pointing out that research was "still not enjoyable," a student observed, "I tend to procrastinate a lot." The student mentioned these two points when asked about research experience, either consciously or unconsciously linking them. If the issue of procrastination could have been addressed more robustly in IL instruction (particularly in sequencing and spacing assignments and instruction sessions over the course of the semester), perhaps the student would have begun to enjoy the process of research. "I'm still a bit of a procrastinator," admitted another student, "but now I have an easier time reading and connecting the information to a bigger picture. As a result, writing research papers has become less strenuous for me." This student acknowledged that sharpening critical thinking skills helped to move her or him beyond procrastination; the more he or she understood about the source material, the less onerous writing the research paper was. 
The fact that persistence is a key trait required in research was also not lost on students. When addressing this issue in their responses to the pre-course test Question 2, the context students used was the recursive nature of research. One observed, "I typically have to go back to the databases to find more information," later admitting, "I think that researching can be frustrating at times. When I can find useful information, though, I am usually very interested by it." The open acknowledgement that it was necessary to revisit the search process was an important step for the student to take, showing that he or she was motivated to continue the task, even if it was difficult. Such a perspective was particularly evident in the following comments by another student: "I will do more research when I've exhausted all of the material I've already found. In summary, my process goes: research, choose topic, research, write, and so on." At this point in his or her university experience, the student understood implicitly that the research process was non-linear, built upon previous actions, and moved forward in unexpected ways. Showing a high degree of self-awareness as a researcher, and a persistent one at that, this student long ago moved beyond the "Principle of Least Effort" (Parker-Gibson, 2001, p. 65).

\section{$\underline{\text { Post-Course Survey Results }}$}

The post-course test responses to Question 2 with respect to persistence or self-efficacy revealed a number of instances of students documenting this trait in accounts of their research process. Students consistently provided examples of specific behaviors and strategies that helped them continue to progress their projects, the critical one being the ability to meet with the librarians, whether in one-on-one sessions or on a visit to the library. One student observed, "When I encountered trouble with online sources, I turned to the University library. Using the help of the librarians, I was able to find books that had material specifically related to what I was trying to write." Before, this individual might have stalled at the online databases stage, but now 
he or she asked for help and recognized the multiplicity of resources that were available to move the project forward. There was no embarrassment or insecurity at seeking assistance from experts who were there to help (Valentine, 2001, p. 111). Something similar was apparent in the following comment: "Before meeting with XXX, I did cursory research in various databases but struggled with finding useful articles. XXX directed me to databases that she thought would be more closely related to my topic and I found that I had much better luck." Mandatory conferencing with the librarian acted as a momentum-reinforcer for student-researchers, building into the course persistence as a trait, and giving students the support to persevere with their topics, research, and writing.

Even more clear than in the pre-course responses to Question 2 was self-efficacy's relationship to recursive learning in post-course comments. One student noted that "As my topic evolved, I continually referred back to the database and books in order to further explore my topic," showing an understanding that knowledge built upon itself and that IL skills helped in retrieving and understanding that knowledge. Detailing the research, reading, and writing process, another student demonstrated its nonlinearity and his or her comfort with that: "I did not take notes on the articles but read them through completely and set aside those I thought would be useful. I then thought about how those articles could be incorporated into my paper before sitting down to write. Once writing, I referred back to the articles often." The student displayed a sense of ease in understanding that the whole research process was circular, documenting a confidence and persistence in reading and writing about the sources; there was no panic evident here, rather a mastery over the material and how to use it. A number of students appeared to have internalized that the research process was nonlinear and sometimes unpredictable but rewarded the researcher who was willing to stick with the project and build on the skills he or she has 
acquired. Perhaps the most eloquent description of the IL concept was this comment from a student, whose persistence marked how advanced he or she was as a researcher and writer: "I have realized that my starting point does not have to be where I end up. That as I write, my plan and focus can change and morph into something more."

\section{$\underline{\text { Student Self-Efficacy in Practice: Pre- and Post-Test Results }}$}

When the pre- and post-course test qualitative data from Question 2 were compared to the pre- and post-course test quantitative data of Question 6 (Appendix C), it became clear that perseverance and self-efficacy were recognized as crucial by students. Asked what they would do if they ran into difficulty with their research, $100 \%$ of respondents in both the pre- and postcourse tests noted that they would "Generate new keywords based on terms located in articles, article bibliographies, and database subject heading fields," all strategies that were explicitly addressed in IL instruction. At the end of the Capstone course, student sentiment about persistence seemed to have become more durable, as post-course test results showed that smaller percentages overall of respondents were willing to even try other alternatives even if they ran into difficulty with their research. They understood that generating new keywords was likely eventually to yield positive results: the choice of generating a new topic went from $35.29 \%$ in the pre-course test to $28.57 \%$; the choice of trying a Google search decreased from $23.53 \%$ to $14.29 \%$ pre- to post-course test; and "other" slid from $35.29 \%$ to $21.43 \%$. Students now had experience and guidance in changing their approaches to the research process - as was clear from their comments to Question 2 on the post-course test - and were mostly comfortable with robust IL strategies and skills. Despite hurdles, students showed a high degree of willingness to persist in their research using effective research strategies. 


\section{Students' Research Papers: Outcomes in Practice}

Although this study is focused on describing and analyzing a survey of students' confidence in and perceptions of IL instruction, the colleagues' goal is to improve students' IL outcomes through this instruction. Attention, therefore, should briefly turn to how some students applied their knowledge in their research projects (Appendix B) after they had participated in the scaffolded IL instruction described above. The Annotated Bibliographies were a heuristic to enable students to better understand and deploy research skills in their final research projects. When these papers (nine in total, taken from the Fall 2015 semester) were examined at the end of the course, the English teacher looked for the following elements in students' handling, incorporation, and comprehension of sources: correctness and accuracy; appropriateness; and confidence (which, difficult to quantify, could be understood as "readability" because a quote that has been inelegantly incorporated might reflect a student's insecurity about how to place it in the essay).

Of the final research projects examined by the English teacher for correctness and accuracy in use of sources and citation conventions, two-thirds had no errors. That is, MLA format was applied correctly (in both in-text and Works Cited contexts), and sources were incorporated accurately (with attention, for example, to grammatical consistency between student text and quoted material). It appeared that the colleagues' workshops on citation format and incorporation of secondary sources had been effective in this area. It should be noted that, in addition to these workshops, the English teacher alone also devoted half of a three-hour class period to a "Citation Clinic," where students were invited to revise their drafts according to the information she presented on citation conventions and incorporation of quotes. Both these learning opportunities appeared to have had a positive effect on student learning outcomes. 
When students' papers were looked at for the appropriate use of sources, the English teacher attempted to determine if each source was a fitting choice to support the points the students were making in their essays. The overall assessment was reassuring, in that over $90 \%$ of students used sources which appropriately underpinned or strengthened their arguments. This demonstrates that students were able to comprehend the secondary material, most of which was written in an academic register with which they were initially less familiar and comfortable. Therefore, the reading comprehension activities, such as summary and evaluation of scholarly sources, embedded in the IL instruction appear to have concretely helped students navigate and, indeed, participate in the varied discourse communities of their sources.

Arguably the "highest-order" skill which was asked of students in terms of their use of secondary materials was how they incorporated them into their research projects. Just how readable were the papers? How confident were students in the way they used their sources? Here, outcomes were mixed. Students' incorporation of external material ranged from fluent and confident: "Anderson reports that fashion industries believe that vocal fry is 'damaging the professional image of young women' (1)"; to adequate: "Company CEO Masaaki Tsuya explained that 'Especially for our young employees, we're going to tell them that English is a must if they want to move up the ladder' (Einhorn)"; to somewhat awkward: "In an article that focuses on the role of SSR [Sustained Silent Reading] it says, 'Two primary goals of silent reading instruction and, conversely, for learning to read silently are those of efficiency and attitude. Efficiency refers to reading with adequate comprehension and rate. Attitude refers to engaging in and enjoying reading' (Sherman and Jones 59)." More than one student demonstrated this range in their papers; it was not always the case that an entire paper had sources incorporated fluently. 
This last example also illustrates another facet of confidence: whether the quote is needed. In her own "Citation Clinic," the English teacher pointed out that quoting material is often not necessary, giving students a series of scenarios where it would be preferable not to quote, and a series of examples where a quote would be helpful. In this latter student example cited above, he or she could have paraphrased the information and still robustly supported the point being made. The outcomes in this area demonstrate, therefore, that students sometimes know how to incorporate quotes readably, but do not do so consistently; and that some students prefer to quote rather than summarize or paraphrase, even if quoting is not necessary and potentially disrupts the flow of their argument. These outcomes could be attributed to insecurity about incorporating quotes, leading the colleagues to wonder whether students have enough tools and confidence in the use of those tools to embed secondary material in their writing in a readable way. Students' perceptions of confidence in their IL skills as demonstrated in the survey versus the application of these skills in their research projects suggest that there is indeed a gap between the two, something which the colleagues must address in future iterations of IL instruction.

\section{Conclusions}

The timing of the XXX English Program Capstone Study is fortuitous, as both the English program and the college as a whole are undergoing curriculum revisions focused on experiential learning and interdisciplinary initiatives. Because English faculty are in the process of re-envisioning course sequences and developing a new major, instruction librarians are poised to weave IL and library instruction into the discussion. The adoption of the ACRL Framework in January of 2016 provides a further impetus for revamping IL instruction in the English program. 
The six frames outline a conceptual structure which can serve as a touchstone for a cohesive IL program, one focused on moving students from the IL practices of the novice researcher to the learning dispositions of the expert during the course of their program of study. Instruction librarians and English program faculty members need to map the competencies from the ACRL Standards document (2000) to the learning dispositions outlined in the new Framework (2016), and adjust IL program goals and outcomes accordingly, informed by the results of this survey.

The student comments provided in the survey and their application in research papers should underpin all of these plans as the colleagues seek to address deficits in students' IL skills and levels of confidence. After careful review and analysis of the survey results and of students' research projects, a number of key issues need to be addressed by the coauthors as they move forward with future IL initiatives and instruction.

\section{Broaden Scope of Study}

This exploratory study needs to be expanded to other student populations, surveying and gathering feedback from Capstone students throughout the English program and across the disciplines, and assembling more student artifacts (including Annotated Bibliographies and research projects in English courses) for perception-practice comparison purposes. The researchers need to determine if what they saw in this small population is typical of graduating seniors in the college as a whole.

\section{Deploy Point-of-Need Instruction Using Authentic Writing Contexts}

In addition to planning future research, the colleagues can make immediate changes to their instructional approach with students in English Capstone courses to address the findings of 
this study. They must construct meaningful IL instruction which meets students where they are in terms of their experience, comfort level, and competence. Such instruction needs to demonstrate in a way which resonates personally with students that they have something at stake in the process. The ACRL Framework's focus on metaliteracy can help students see themselves as participants in the academic conversation. Using the frame "Scholarship as Conversation," librarians can help students view their research projects not just as assignments turned in for a grade, but as documents that contribute to the collective knowledge in a particular field of study. IL activities embedded in authentic writing contexts that students themselves have selected and therefore find meaningful are the keys to demonstrating to them that research and IL are not boxes to be checked, nor mazes to be navigated to determine "what the professor wants." Instead, they are critical, purposeful, personally-engaging lifelong learning skills which students will carry with them long after graduation. Further, such activities will help move the students to a place of learning where their focus is not on the tools of research, but rather on the skills of critical thinking that are embedded in the research process.

\section{Scaffold Instruction Purposefully and Systematically}

As the coauthors expected, all of the Capstone students had been exposed to multiple IL sessions during their time at the college; indeed, many acknowledged that the review of material helped them recall key elements of the research process. The repetition of skills, however, should be used as a foundation for the introduction of new skills (Radom \& Gammons, 2014), not as an end in itself. Consequently, the coauthors plan to create IL sessions throughout the English program that intentionally build upon skills taught earlier in the course sequence. 


\section{Increase Frequency of One-on-One Research Consultations}

Particularly noteworthy were student statements indicating that one-on-one consultations with the librarian were most effective at moving their research forward. Student comments regarding the benefit of these research meetings confirmed their importance in IL instruction at this level. As a result of this feedback, the colleagues acknowledge that the ratio of in-class workshops to one-on-one librarian consultations needs to be recalibrated, with the instruction librarian serving as an embedded personal research guide who meets with each student multiple times during the semester. Such a model would provide the in-class reinforcement of IL skillsets necessary for a scaffolded learning experience, while also focusing on moving students' individual skill levels further.

Conferences, whether with the librarian or with the English teacher, can be crucial in building students' confidence as well. One student noted in a response to post-course test Question 2, "XXX [XXX, the English teacher and coauthor]'s reminders that it was unlikely we would find exactly what we needed and instead would ourselves write the perfect article were very reassuring." The teacher's observations resonated with this particular student—which was the intent. The goal in saying such a thing to students was to assure them that they had the ability to write something valuable which would contribute to the overall discourse community, making them an expert on that topic. It is important to imbue students with a sense of reassurance, confidence, and achievement at each step of the research process, something which can be most effectively reinforced on a case-by-case basis in conferences tailored to the particular research and writing needs of individual students. 
With specific reference to tool-based skills, the survey demonstrated that there were key areas of confusion and lack of confidence around database searching. Although a number of students felt more confident at the end of the course in their ability to retrieve appropriate material from databases for their own projects, it became clear that they were wayward in selecting appropriate databases given in the survey. There appears, therefore, to be a perception gap between how students feel about their skills and those skills in practice. For the English teacher and instruction librarian, future IL instruction needs to be more robustly focused on database search and retrieval, both within the disciplines with which students are familiar and also outside those disciplines, so students obtain more experience exploring, analyzing, and writing beyond their "comfort zone." The instruction librarians plan to use the frame "Searching as Strategic Exploration" as a basis for teaching database selection and advanced search skills in library instruction sessions throughout the English program course sequence, thus encouraging the development of the learning dispositions discussed in the frame.

\section{Embed Pedagogically-Driven Sequential Assignments in Courses}

The results of the survey revealed a number of comments about procrastination in the pre-course test, but none in the post-course test. A goal for IL instruction should be to build elements in the sequencing of assignments and presentations which advance students in their research projects throughout the semester. Procrastination-which makes self-efficacy very difficult — should be next-to-impossible. Such was the situation in the Capstone course, perhaps explaining why there were no comments about this in the post-course test. The Annotated Bibliography assignment, due early in the course, kick-started students' research process — one of the goals of the assignment. It was critical that students were not given leave to wait until the last 
minute to begin research, but were instead nudged to brainstorm a topic and begin gathering and reading materials on that topic before the halfway-mark of the course.

Furthermore, rough drafts (at varying stages of completion) were due at a number of points in the second half of the semester, and one-on-one conferences with the instruction librarian (for research purposes) and the English teacher (for the purposes of discussing the actual drafts) allowed ample opportunity for students to feel supported as their projects progressed. Even if the drafts were very rough, it was still pointed out to students that they were moving forward and accomplishing their goals. Students also peer edited each other's drafts, allowing them to see the progress and development of their classmates' work. Similarly, the mandatory meetings with the librarian appeared to have truly helped students advance through stickier points in the research process, giving them the confidence to maintain momentum.

The frame "Research as Inquiry" can serve as a paradigm for conversations surrounding procrastination and the research timeline. By encouraging students to "value persistence, adaptability, and flexibility" (ACRL, 2016), instruction librarians can increase students' confidence in their own abilities to complete their task and help them to push through research roadblocks. Though there will always be opportunities to stall in any research project, if specific activities can be embedded in the syllabus to prevent this wherever possible, students will have little chance to do so-whether they are so inclined or not.

\section{Expand Instruction in Summary, Paraphrase, and Incorporating Sources}

Application of skills learned in the IL instruction using secondary materials in students' research projects yielded positive outcomes in terms of correctness, accuracy, and appropriateness. However, students' success in incorporating these sources readably into their 
projects was somewhat hit-or-miss. Although the sample size of the research papers used for comparison purposes was small, larger lessons can be drawn from these projects: students benefit from workshops on how to incorporate secondary sources, and would further benefit from instruction and guidance on elegant embedding of quotes and, most importantly, summary and paraphrase of quoted materials. Using the ACRL Framework, the colleagues plan to emphasize these areas in future IL instruction; an in-depth, librarian-led engagement with the frame "Information Has Value" will encourage students to explore and address issues of source incorporation and plagiarism more mindfully.

\section{Afterword}

The ACRL Framework (2016) provides the colleagues with the philosophical and pedagogical underpinning to advance students' level of understanding of IL concepts. The ACRL Standards (2000) document enumerated the skills and competencies students should master by the Capstone level and informed the questions the co-authors used to gauge the students' IL skill levels. However, the students' nuanced reflections on the research process, as well as the complex nature of their IL strengths and deficits, require a response that moves beyond mere skills acquisition to encompass a broad, holistic understanding of scholarship and academic discourse. The co-authors believe that the Framework provides the conceptual schema necessary for moving students from a rote research practice to a mature, informed understanding of knowledge, and their role in its creation. By heeding the advice and experience of the graduating seniors, and by using the ACRL Framework document as a roadmap, instruction librarians and English faculty will work to ensure students are guided and supported by a robust IL program 
that prepares them for the research and critical thinking necessary in the world beyond the college. 


\section{References}

Association of College \& Research Libraries (ACRL). (2000). Information Literacy Competency Standards for Higher Education. Retrieved from http://www.ala.org/acrl/standards/informationliteracycompetency

Association of College \& Research Libraries (ACRL). (2016). Framework for Information Literacy for Higher Education. Retrieved from http://www.ala.org/acrl/standards/ilframework

"At a Glance." Retrieved from http://XXX. Retrieved on 11 August, 2016.

Bandura, A. (1977). Self-efficacy: Toward a unifying theory of behavioral change. Psychological Review, 84, 191-215. http://dx.doi.org/10.1037/0033-295x.84.2.191

Bandyopadhyay, A. (2013). Measuring the disparities between biology undergraduates' perceptions and their actual knowledge of scientific literature with clickers. The Journal of Academic Librarianship, 39, 194-201. http://dx.doi.org/10.1016/j.acalib.2012.10.006

Bordonaro, K. and Richardson, G. (2004). Scaffolding and reflection in course-integrated library instruction. The Journal of Academic Librarianship, 30(5), 391-401. http://dx.doi.org/10.1016/j.acalib.2004.06.004 
Denison, D. R. and Montgomery, D. (2012). Annoyance or delight? College students' perspectives on looking for information. The Journal of Academic Librarianship, 38(6), 380-390. http://dx.doi.org/10.1016/j.acalib.2012.08.007

Detlor, B., Booker, L., Serenko, A. \& Julien, H. (2012). Student perceptions of information literacy instruction: The importance of active learning. Education for Information, 29,147-161. Retrieved from http://www.iospress.nl/journal/education-for-information/

Donham, J. (2014). College ready — what can we learn from first-year college assignments? An examination of assignments in Iowa colleges and universities. School Library Research,17, 1-21. Retrieved from http://www.ala.org/aasl/slr

Dubicki, E. (2015). Writing a research paper: Students explain their process. Reference Services Review, 43(4), 673-688. http://dx.doi.org/10.1108/rsr-07-2015-0036

XXX, C.; XXX, R.; XXX, A.; XXX, K.; \& XXX, J. (2016) XXX

Ganley, B. J., Gilbert, A. \& Rosario, D. (2013). Faculty and student perceptions and behaviors related to information literacy: A pilot study using triangulation. The Journal of Information Literacy, 7(2), 80-96. http://dx.doi.org/10.11645/7.2.1793 
Gross, M. \& Latham, D. (2007). Attaining information literacy: An investigation of the estimates of skill, and library anxiety. Library \& Information Science Research, 29, 332-53. http://dx.doi.org/10.1016/j.lisr.2007.04.012

Gross, M. \& Latham, D. (2009). Undergraduate perceptions of information literacy: Defining, attaining, and self-assessing skills. College \& Research Libraries, 70(4), 336-350. http://dx.doi.org/10.5860/crl.70.4.336

Jackson, C. (2013). Confidence as an indicator of research students' abilities in information literacy: A mismatch. The Journal of Information Literacy, 7(2), 149-152. http://dx.doi.org/10.11645/7.2.1848

Kim, S. U. \& Shumaker, D. (2015). Student, librarian, and instructor perceptions of information literacy instruction and skills in a first year experience program: A case study. The Journal of Academic Librarianship, 41, 449-456. http://dx.doi.org/10.1016/j.acalib.2015.04.005

Klentzin, J. C. (2010). The borderland of value: Examining student attitudes towards secondary research. Reference Services Review, 38(4), 557-570. http://dx.doi.org/10.1108/00907321011090728 
Kwon, N. (2008). A mixed-methods investigation of the relationship between critical thinking and library anxiety among undergraduate students in their information search process. College \& Research Libraries, 69(2), 117-131. http://dx.doi.org/10.5860/crl.69.2.117

Malenfant, C. \& Demers, N. E. (2004). Collaboration for point-of-need library instruction. Reference Services Review, 32(3), 264-273. http://dx.doi.org/10.1108/00907320410553678

Molteni, V. \& Chan, E. K. (2015). Student confidence/overconfidence in the research process. The Journal of Academic Librarianship, 41, 2-8. http://dx.doi.org/10.1016/j.acalib.2014.11.012

O'Neill, P., Adler-Kassner, L., Fleischer, C., \& Hall, A. (2012). Creating the Framework for Success in Postsecondary Writing. College English, 74, 520-33. Retrieved from http://www.ncte.org/journals/ce

Parker-Gibson, N. (2001). Library assignments: Challenges students face and how to help. College Teaching, 49, 65-70. Retrieved from http://www.tandfonline.com/loi/vcol20

XXX, S. F. \& XXX, C. B. (2004) XXX

XXX, S. F. \& XXX, C. B. (2005/2006) XXX 
XXX, S. F. \& XXX, C. W. (2011) XXX

Polkinghorne, S. \& Wilton, S. (2010). Research is a verb: Exploring a new information literacy embedded undergraduate research methods course. The Canadian Journal of Information and Library Science, 34, 457-473. http://dx.doi.org/10.1353/ils.2010.0008

Radom, R. \& Gammons, R. W. (2014). Teaching information evaluation with the Five Ws: An elementary method, an instructional scaffold, and the effect on student recall and application. Reference \& User Services Quarterly, 53(4), 334-347. http://dx.doi.org/10.5860/rusq.53n4.334

Valentine, B. (2001). The legitimate effort in research papers: Student commitment versus faculty expectations. The Journal of Academic Librarianship, 27, 107-115. http://dx.doi.org/10.1016/s0099-1333(00)00182-8

Wilkinson, K. and Crews, T. B. (2009). Business report writing: students' perceptions of their ability to succeed in an online environment vs. students' performance in an online course. International Journal of Information and Communication Technology Education, 5(4), 68-77. http://dx.doi.org/10.4018/978-1-60960-150-8.ch022 


\title{
Appendix A
}

XXX XXX

Engl 791: English Grammar

Annotated Bibliography Assignment Sheet

\section{English Language Research Paper Annotated Bibliography Guidelines}

\author{
Due Mon. 19 Oct. in your Conference
}

\section{Instructions:}

After gathering a series of journal articles and books to form the foundation of your research, you will need to carefully read these materials and assess whether they will be valuable to you and, if so, how you will use them in your research paper. To this end, you'll need to craft an Annotated Bibliography, the purpose of which is help you

- Learn about your topic

- Formulate a thesis

- Situate yourself in a specific academic field of interest

- Help others who are interested in your topic get a grounding in its basics

- Communicate to me that you are finding your feet in your particular area of research interest

Be sure to use MLA format for your Annotated Bibliography. See SFH 78-80 for sample Annotated Bib in MLA format, as well as page from sample Annotated Bib in handout. For information on documenting in MLA format journal articles from online indexes and full-text databases, see SFH 656-716.

There is no specific maximum number of sources you need to have for your Annotated Bibliography; however, you must have at least five sources, and they must be a variety of materials: journal articles, as well as books/chapters from books. Note: Please be sure to understand the difference between journals and magazines: journals are written for a specialist academic audience; magazines are written for laypeople. Please use journal articles, not magazine articles, wherever possible. When annotating each source, be sure to follow the format of the handout illustrating a sample Annotated Bibliography.

\section{Guidelines for Annotations:}

For each source:

- summarize its content in a few sentences. Note: be sure not to plagiarize and don't quote directly from the source. For more on summary and paraphrase, see SFH 614-33, the handout on Annotated Bibliographies, and the related website http://owl.english.purdue.edu/owl/resource/563/1/ 
- assess how it relates to the other materials you've been reading; what kind of source it is; whether the research is reliable, biased, out of date. See handout on Annotated Bibliographies for more on this.

- reflect on whether this source is useful for your research; why or why not; how you think you will use it in your paper. Again, see handout on Annotated Bibliographies for more on this.

Purdue University's Online Writing Lab (OWL) has a whole section devoted to Annotated Bibliographies, and, in particular, the three categories listed above. Please review it before beginning your own Annotated Bibliography:

\section{http://owl.english.purdue.edu/owl/resource/614/01/}

Type and double space your Annotated Bibliography. See Syllabus for instructions on presentation and format of written assignments.

Remember, I'm available for one-on-one consultations about brainstorming, narrowing your research, and any other questions related to the research process. Please let me know if I can help you in any way. Contact me via email for the promptest response. 


\section{Appendix B}

XXX XXX

Engl 791: English Grammar

Assignment Sheet

\section{English Language Research Paper Guidelines}

Topic Proposal due Mon. 5 Oct.; Detailed Outline due Mon. 16 Nov.; Rough Draft due Mon. 23 Nov.; Revised Rough Draft due Mon. 30 Nov.; Final Draft due Mon. 14 Dec.

\section{Instructions:}

Choose your own topic for this research paper, paying careful attention to the guidelines given below. Your paper should take the form of an essay directed by a clear argument or thesis. You can choose any topic that's related to some aspect of the English Language (possible examples are given below).

Please be sure that you take an arguable stance on a topic. For example, this paper should not be a review or a historical overview of a topic; it should instead make a defendable argument about the topic. Thus, you wouldn't want to write about the history of African-American English, but rather you'd want to take a stand (that some would disagree with) on some aspect of AfricanAmerican English. You'd then go on to defend that stand in a persuasive manner using evidence to support your position.

As you write, concentrate primarily on argumentation (stating your position and then supporting it credibly), and interpretation, remembering to quote, summarize, and paraphrase from the sources you choose to cite. If you quote directly from your source material, use the author's name and the page number in parentheses, following MLA format.

\section{Example:}

Typical of the Highland Scots dialect of Barra, an island in the Outer Hebrides, is an emphasis on its "fine, musical lilt" (McCrum 142).

You'll also need to provide us with a complete Works Cited page in MLA format at the end of your paper. Be sure to list in alphabetical order all the works you've cited (either directly or indirectly) in your paper. A Works Cited page is different from a Bibliography; the latter lists all works you've looked at in the course of your research, whereas the former documents only those works you've actually cited in your essay.

It's very important to narrow carefully the scope of your argument to fit the page limits (10 pages; grad students and Capstone students 15pp). I will evaluate each essay on: 
- overall persuasiveness of your argument (development of your points, logical coherence of your essay, insights you develop based on your understanding of the evidence)

- use of evidence (its relevance to your argument, your ability to elegantly incorporate it into your paper)

- precision and focus of your argument

- organization

- grammar, mechanics, tone, and style

Type and double space your response. See Syllabus for instructions on presentation and format of written assignments.

\section{Ideas for Possible Topics:}

- Literary use of language varieties (e.g. Twain; Shakespearean English)

- Classroom practices and English Language (the "Whole Language" debate, phonics)

- How people use language to craft identities for themselves

- Language and politics (the debate about Ebonics, "standards"--see next prompt)

- Language and "standards" (the debate about Standard English)

- Language varieties (slang, regionalisms, ethnic dialects, profanity)

Remember, I'm available for one-on-one consultations about brainstorming, outlining, and drafting of your papers. Please let me know if I can help you in any way. Contact me via email for the promptest response. 


\section{Appendix C: Survey Tool}

\section{Reflective Question: Pre-Course}

2) Looking back over your academic experiences in the English program at XXX, take some time to reflect on how your skills as a researcher have developed or been enhanced. Use the following discussion prompts to organize your thoughts and structure your response. In your response, please answer each prompt completely: a thoughtful response may be approximately three paragraphs long.

-Talk about your typical research process for English papers requiring outside sources. In what ways has information literacy instruction impacted your research and writing process so far? Please give examples.

-Describe yourself as a researcher now that you are embarking on your Capstone experience.

\section{Reflective Question: Post-Course}

2) Looking back over the entire semester, take some time to reflect on how your skills as a researcher have developed or been enhanced. Use the following discussion prompts to organize 
your thoughts and structure your response. In your response, please answer each prompt completely: a thoughtful response may be approximately three paragraphs long.

- Talk about your research strategy for your paper. In what ways did the information literacy instruction impact your research and writing process? Please give examples.

- Please discuss the experience of writing the Annotated Bibliography. How did the process impact your research and your writing?

- Describe yourself as a researcher now that you have completed your Capstone experience.

\section{Multiple Choice Questions (Pre-course and Post-course)}

You are writing a paper about teaching ESOL to recent immigrant students in the K-12 classroom. Your instructor has required you to use academic journal articles as sources for this paper. Please answer the questions below with this scenario in mind.

3) How do you determine what kind of information you need and how to search for it?

a) Generate an idea tree

b) Note down synonyms, antonyms, concepts as keywords and phrases

c) Determine problems or issues linked to your project or paper 
d) Note down stakeholders (e.g. students, teachers, parents, administrators)

e) All of the above

4) You are preparing to search the library databases for articles on your topic. Choose the single best search string from the examples below.
a) teaching ESOL to recent immigrant students in the K-12 classroom
b) ESOL or ESL or ELL
c) ESOL and (teaching or instruction) and K-12 and immigrant*
d) teaching strategies with ESOL students

5) How do you efficiently and effectively access relevant, scholarly, current (last five years) information for your project on teaching ESOL to recent immigrant students in the K-12 classroom.

a) Use the following databases to find information on the topic: ERIC, MLA, LLBA, Sociological Abstracts

b) Use the following databases to find information on the topic: LION, MLA, JSTOR, Project Muse

c) Use the following databases to find information on the topic: Lexis-Nexis, CQ Researcher, PAIS, and the New York Times Digital Archive

d) All of the above 
6) What do you do if you are not finding research that looks helpful at this point?

a) Generate new keywords based on terms located in articles, article bibliographies, and database subject heading fields.

b) Determine that your topic may not be viable for a research project; choose a new topic and begin again.

c) Determine that your topic may not be covered in the XXX databases; execute a Google search to see what is available.

d) None of the above

7) What evaluative criteria do you use on articles that you have located? Click all that apply.
a) Relevance
b) Credibility
c) Perspective
d) Length
e) References
f) Purpose

8) In your Annotated Bibliography for the research paper on ESOL teaching, how do you show the instructor that you understand the content of an article? Check all that apply. 

a) Summarize the article
b) Paraphrase the article
c) Quote the article
d) Explain how the source will be used in your research paper

9) What do you do if one credible scholarly article appears to undermine or contradict your project's thesis and your other research?
a) Accommodate the article in your project by acknowledging and engaging with its position
b) Reshape your thesis to that article's point of view
c) Decide to use only those articles that support your position
d) Determine that your thesis is unworkable and change topics

10) Which of these practices might your instructor consider to be an unethical use of sources or a form of academic dishonesty? Check all that apply.
a) Having more than $10 \%$ of your final paper consist of quoted material
b) Paraphrasing material from a source and not citing it accurately
c) Incomplete or inconsistent citations
d) Submitting a paper used for another course 


\section{Applied Skills Questions (Pre-course and Post-course)}

11) You have narrowed your topic on ESOL teaching to focus on using ESOL immigrant students' own cultural experiences and life stories as the basis for writing instruction. Which article below is the most appropriate for your topic, and why?

a) Peterson, Shelley Stagg and Daphne Heywood. "Contributions of Families' Linguistic, Social, and Cultural Capital to Minority-Language Children's Literacy: Parents', Teachers' and Principals' Perspectives." Canadian Modern Language Review 63.4 (2007): 517-538.

Abstract: A discussion of assumptions regarding minority-language parents' linguistic, social, and cultural capital in supporting their children's literacy development.

b) Souryasack, Rassamichanh and Jin Sook Lee. "Drawing on Students' Experiences, Cultures and Languages to Develop English Language Writing: Perspectives from Three Lao Heritage Middle School Students." Heritage Language Journal 5:1 (2007): 79-97.

Abstract: This study examines the second language writing experiences of three long-term ESL learners of Lao heritage who took part in a nine-week writing workshop. The authors argue for the need to value, validate, and make visible students' personal experiences, including their heritage cultures and languages, as a critical strategy in motivating students to write.

c) Stewart, Mary Amanda. "Writing with Power, Sharing Immigrant Stories: Adult ESOL Students Find Their Voices through Writing." TESOL Journal 1:2 (2010): 269-283. 
Abstract: After noting the disconnect between students' passionate oral stories and their lifeless writing, an adult education instructor made specific instructional and curriculum changes in an ESOL reading and writing course.

d) Reeves, Jenelle. "A Sociocultural Perspective on ESOL Teachers' Linguistic Knowledge for Teaching." Linguistics and Education: An International Research Journal 20:2 (2009): 109125.

Abstract: Teachers' biographies, including their experiences as language learners, shape their knowledge base for teaching English to speakers of other languages (ESOL). This study interrogates one element of that knowledge base: teachers' linguistic knowledge for teaching.

You are writing your paper on ESOL teaching strategies. You have read the following article and want to use an observation from it in a paragraph in your paper. Read the original quote and Works Cited citation below, read the three sample paragraphs that follow, and then answer questions 12 through 14.

\section{Original text of source:}

"In other words, students increased their knowledge of the target words in the intervention, which demonstrated that strategies that had previously been shown to be effective with general vocabulary words and younger students are also effective with abstract academic words and adolescent ELLs." 
Citation in Works Cited page at the end of the research paper:

Townsend, Dianna. Building Academic Vocabulary in After-School Settings: Games for Growth with Middle School English-Language Learners. Journal of Adolescent \& Adult Literacy 53.3 (2009): 242-51.

Three sample paragraphs where source is integrated into a research paper on teaching ESOL students:

Paragraph A

It is also possible to use teaching techniques and heuristics that have been employed for younger students and adapt them to an older ESOL population. "In other words, students increased their knowledge of the target words in the intervention, which demonstrated that strategies that had previously been shown to be effective with general vocabulary words and younger students are also effective with abstract academic words and adolescent ELLs" (Townsend 249). So a teacher need not reinvent the wheel when she is gathering resources to help her ESOL students build their vocabulary. She may well be able to review heuristics and teaching strategies targeted for younger students and tweak them to successfully apply to older ESOL students.

\section{Paragraph B}

It is also possible to use teaching techniques and heuristics that have been employed for younger students and adapt them to an older ESOL population. For example, students improved their understanding of the words in the exercises, which showed that methods that had in the past been demonstrated to be useful with everyday terms and elementary students 
were also useful with more advanced terminology and teenaged ESOL students (Townsend 249).

Middle school ESOL students' success in improving their understanding and application of academic words (such as analyze, process, and specific) through intensive, scaffolded exercises and games replicates improvement seen in younger students' understanding of everyday words. So a teacher need not reinvent the wheel when she is gathering resources to help her ESOL students build their vocabulary. She may well be able to review heuristics and teaching strategies targeted for younger students and tweak them to successfully apply to older ESOL students.

\section{Paragraph C}

It is also possible to use teaching techniques and heuristics that have been employed for younger students and adapt them to an older ESOL population. As Diana Townsend noted when assessing the impact of her voluntary after-school Language Workshop initiative on middle-school ESOL students, those "students increased their knowledge of the target words in the intervention, which demonstrated that strategies that had previously been shown to be effective with general vocabulary words and younger students are also effective with abstract academic words and adolescent ELLs" (249). Middle school ESOL students' success in improving their understanding and application of academic words (such as analyze, process, and specific) through intensive, scaffolded exercises and games replicates improvement seen in younger students' understanding of everyday words. So a teacher need not reinvent the wheel when she is gathering resources to help her ESOL students build their vocabulary. She may well be able to review heuristics and teaching strategies targeted for younger students and tweak them to successfully apply to older ESOL students. 
12) Describe how effectively the source material is used in Paragraph A.

13) Describe how effectively the source material is used in Paragraph B.

14) Describe how effectively the source material is used in Paragraph $C$.

15) Which paragraph uses the source material most effectively?
a) Paragraph A
b) Paragraph B
c) Paragraph C 